\title{
Sequential and Selective Detection of Two Molecules with a Single Solid-Contact Chronopotentiometric Ion-Selective Electrode
}

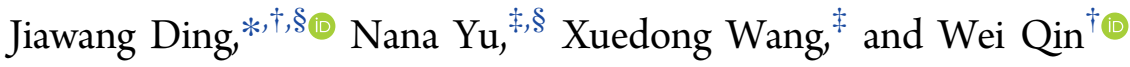

${ }^{\dagger}$ Key Laboratory of Coastal Environmental Processes and Ecological Remediation, Yantai Institute of Coastal Zone Research (YIC), Chinese Academy of Sciences (CAS); Shandong Provincial Key Laboratory of Coastal Environmental Processes, YICCAS, Yantai, Shandong 264003, People's Republic of China

${ }^{*}$ Department of Environmental Sciences, Key Laboratory of Watershed Science and Health of Zhejiang Province, Wenzhou Medical University, Wenzhou 325035, People's Republic of China

\section{Supporting Information}

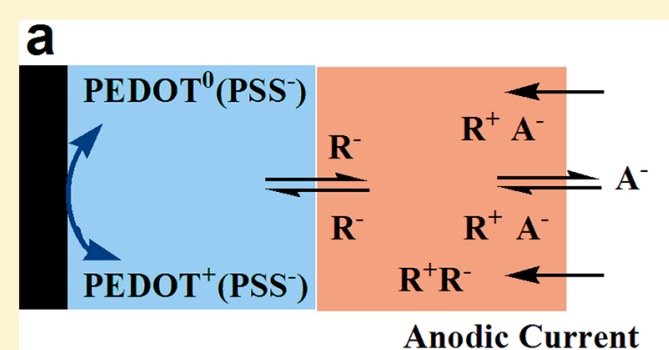

Anodic Current

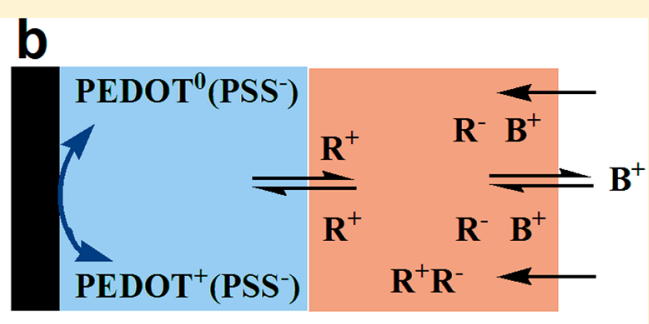

Cathodic Current

ABSTRACT: A polymeric membrane ion-selective electrode (ISE) is typically designed for the determination of one specific ion using a conventional method. In this work, we demonstrate a simple, versatile, and sensitive platform for simultaneous detection of two molecules with a single ISE. Under a series of periodic galvanostatic polarization, a solid-contact ISE without ion exchanger properties under zero-current conditions has been successfully used for simultaneous detection of two opposite charged ions with high sensitivity, good selectivity, and fast reversibility. By integration of biorecognition elements with the potentiometric measurement, highly sensitive and selective detection of a broad range of different molecular targets can be predicted. As a proof of concept, a potentiometric genosensor based on magnetic beads-enzyme sandwich assay has been designed for sensitive and selective detection of pathogenic bacteria Escherichia coli O157:H7 and Staphylococcus aureus. Under optimal conditions, two bacteria nucleic acid sequences can be detected simultaneously with high sensitivity and good selectivity by using a single solid-contact potentiometric ISE. The detection limits of Escherichia coli O157:H7 DNA and Staphylococcus aureus DNA are 120 and $54 \mathrm{fM}(3 \sigma)$, respectively. Because of its simplicity, this potentiometric technique based on ISE can be an attractive tool or detector to perform two analyte measurements.

$\mathrm{P}$ otentiometry based on ion-selective electrodes (ISEs) has emerged as a valuable tool for selective detection of target ions in biological and environmental samples. ${ }^{1-4}$ Conventionally, an ISE was interrogated under zero-current conditions for a specific ion. ${ }^{5}$ As an alternative, an exciting new class of dynamic ISEs operated in nonzero current mode has become a very active field of research. ${ }^{6,7}$ Attractive methodologies include, but are not limited to, chronopotentiometry, 8,9 thinlayer voltammetry, ${ }^{10,11}$ and a constant potential coulometry. ${ }^{12-14}$ In these attractive methodologies, open-circuit potential, $^{9}$ chronopotential, ${ }^{8,9}$ transition time, ${ }^{15}$ charges of transient current pulse, ${ }^{16}$ and voltammetric current ${ }^{10,11}$ have been served as a readout. Because of their versatility in detecting and manipulating ions, the dynamic ion-selective sensors may offer a distinct multianalyte capability.

By coupling thin-layer ion-selective membranes with voltammetry, ion-transfer stripping voltammetry for ions with nanomolar detection limits has been proposed by Amemiya et al. ${ }^{17}$ In a similar configuration, $\mathrm{Si}$ and Bakker found that both cation and anion transfer can be observed in the same voltammogram. ${ }^{18}$ Recently, Bakker's group introduced a thinlayer ionophore-based membrane that allows one to selectively and simultaneously detect the activities of multiple ions. ${ }^{19}$ More importantly, the performance of thin-layer membrane was experimentally and theoretically elucidated. ${ }^{20-22}$

In contrast to the voltammetric ISE, potentiometric ISEs with multianalyte capability have received little notice. Bakker's group introduced the chronopotentiometric pulstrodes, which couple the feature of instrumental control of ion transfer with the inherent advantages of zero-current potentiometry. ${ }^{23}$ This pulsed galvanostatic technique can be adopted as a mean to alter the selectivity, sensitivity, reversibility, and upper detection limit of the ISEs. ${ }^{24-27}$ Interestingly, this technique can be an attractive tool to perform two or more analytes measurements. Multicomponent analyses of the mixtures of protamine fragments were achieved by separation with a column and

Received: August 29, 2017

Accepted: January 17, 2018

Published: January 17, 2018 
subsequent potentiometric measurement of each separated target with a fully reversible pulstrode. ${ }^{28}$ These potentiometric methods, however, are still limited to the detection of ions. Therefore, as a detector or an individual transducer, a single electrode that can perform two or more analytes measurements is still highly required. Moreover, their applications to detect a broad range of different molecular targets have not been explored.

In recent years, although many efforts have focused on sensing of clinically relevant ions with ISEs, their applications for potentiometric biosensing have also attracted considerable attention because of their versatility and applicability. ${ }^{29-33}$ Indeed, the incorporation of bioreceptors into the potentiometric biosensors based on ISEs enables the detection of a wide range of targets including ions, small molecules, and even whole cells. ${ }^{34-37}$ With the motivation of developing a potentiometric sensing protocol with dual or multianalyte capability, we herein report, for the first time, a galvanostatically controlled solidcontact potentiometric ISE for simultaneous detection of two biomolecules. By integration of biorecognition elements with pulstrodes, highly sensitive and selective measurements of a broad range of different molecular targets can be predicted. As a proof of principle, a potentiometric genosensor based on a magnetic beads-enzyme sandwich assay was designed for the sensitive and selective detection of pathogenic bacteria Escherichia coli O157:H7 and Staphylococcus aureus. To the best of our knowledge, this is the first report of simultaneous detection of dual DNA sequences using a single solid-contact ISE.

\section{EXPERIMENTAL SECTION}

Reagents and Materials. High molecular weight poly(vinyl chloride) (PVC), 2-nitrophenyl octyl ether (o-NPOE), tetradodecylammoniumtetrakis(4-chlorophenyl)-borate (ETH 500), poly(3,4-ethylenedioxythiophene)-poly(styrenesulfonate) (PE DOT-PSS, $1.3 \%$ in $\mathrm{H}_{2} \mathrm{O}$, high-conductivity grade), $p$ nitrophenyl phosphate disodium salt hexahydrate ( $p$-NPP), tetramethylbenzidine (TMB), $\mathrm{H}_{2} \mathrm{O}_{2}$, and tris(hydroxymethyl)aminomethane (Tris) were purchased from Sigma. Horseradish peroxidase (HRP)-conjugated streptavidin, alkaline phosphatase (AP)-conjugated avidin, and DNA sequences were purchased from Shanghai Sangon Biotechnology Co. Ltd. (Shanghai, China). Streptavidin labeled magnetic beads (MB, $10 \mathrm{mg} \mathrm{mL}{ }^{-1}$ ) with an average particle size of $1.0 \mu \mathrm{m}$ were purchased from BioCanal Scientific Inc. (Jiangsu, China). Ten $\mathrm{mM}$ Tris- $\mathrm{HCl}$ buffer solution $(\mathrm{pH} 7.4)$ containing $1.0 \mathrm{mM}$

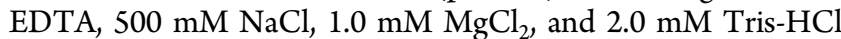
buffer solution ( $\mathrm{pH} 8.0)$ was used for DNA hybridization and potentiometric detection, respectively.

ISE Preparation and EMF Measurements. The polymeric ion-sensitive membranes contained 10 wt \% ETH 500, 45 wt $\% o$-NPOE, and $45 \mathrm{wt} \%$ PVC. The membrane electrodes were prepared as described before. ${ }^{38}$ Ten microliters of PEDOT-PSS was dropped on the glass carbon (GC) electrode surface and air-dried. Solid-contact ISEs were prepared by drop-casting $80 \mu \mathrm{L}$ of the membrane cocktail on the GC/ PEDOT-PSS electrodes. After being dried for $12 \mathrm{~h}$ at room temperature, the ion-selective electrodes were conditioned in $2.0 \mathrm{mM}$, Tris- $\mathrm{HCl}$ buffer solution $(\mathrm{pH} 8.0)$ overnight. All of the measurements were carried out on a CHI 760D electrochemical workstation (Shanghai Chenhua Apparatus Corporation, China) using a conventional three-electrode system. The pulsed galvanostatic sensing procedures were employed as described before with some modification. ${ }^{9}$ Briefly, the opencircuit potential was first measured for $1 \mathrm{~s}$. Next, an external anodic current of $5 \mu \mathrm{A}\left(71 \mu \mathrm{A} \mathrm{cm}^{-2}\right)$ with a duration of $1 \mathrm{~s}$ was applied for the extraction of the anion into the membrane to produce the chronopotentiometic response. After that, a controlled voltage at the open-circuit potential (with a duration time of $120 \mathrm{~s}$ ) in the absence of analyte was used to refresh the membrane. Similar measurement procedures were used for the cation. However, a cathodic current of $5 \mu \mathrm{A}\left(71 \mu \mathrm{A} \mathrm{cm}^{-2}\right)$ with a duration of $1 \mathrm{~s}$ facilitated the extraction of the cation into the membrane. Macro-command controlled the switches of all of the above sensing procedures for three continuous measurements. The Tris- $\mathrm{HCl}$ buffer solution $(2.0 \mathrm{mM}, \mathrm{pH} 8.0)$ was used as the medium for all of the measurements.

Conjugation of Capture Probes on MBs. The sequences of synthetic oligonucleotides and targets are listed in Table S1. E. coli O157:H7 and Staphylococcus aureus synthetic probes and targets were chosen according to the literature. ${ }^{39}$ For each bacteria strain, the capture and signaling sequences were selected within the sequence of a gene encoding a strainspecific toxin. These genes were chosen considering the frequency of the presence of the different bacterial strains. All oligonucleotides were synthesized by Shanghai Sangon Biotechnology Co. Ltd. (Shanghai, China). The oligonucleotides were heated at $90{ }^{\circ} \mathrm{C}$ in Tris buffer for $5 \mathrm{~min}$, which was followed by cooling at room temperature.

The capture sequences were immobilized on magnetic beads via biotin-avidin interactions. Briefly, $200 \mu \mathrm{L}$ of $5.0 \times 10^{-5} \mathrm{M}$ biotin labeled capture sequences was incubated with $10 \mathrm{mg}$ $\mathrm{mL}^{-1} \mathrm{MBs}$ in buffer for $30 \mathrm{~min}$ at room temperature. After that, the MBs were separated by a magnet, and washed three times with buffer. The capture sequences modified magnetic beads were kept in $200 \mu \mathrm{L}$ of hybridization buffer at $4{ }^{\circ} \mathrm{C}$ for further use.

Detection of Target DNA. Thirty microliters of target DNA at various concentrations was added into $30 \mu \mathrm{L}$ of capture DNA modified MBs and incubated for $1 \mathrm{~h}$ with gentle shaking. The target DNA-conjugated MBs then were washed three times with hybridization buffer. Afterward, the target DNA-conjugated MBs were immersed in $30 \mu \mathrm{L}$ of the hybridization buffer with $10^{-6} \mathrm{M}$ signaling probe and incubated for $1 \mathrm{~h}$ with gentle shaking. After washing and separation, $30 \mu \mathrm{L}$ of $0.02 \mathrm{mg} \mathrm{mL} \mathrm{mRP}^{-1} \mathrm{HR}$-conjugated streptavidin and APconjugated avidin was added into the signal DNA-conjugated MBs for $30 \mathrm{~min}$ to prepare the magnetic beads-enzyme sandwich assay for Escherichia coli O157:H7 and Staphylococcus aureus target sequences, respectively.

The signaling probe conjugated MBs with different concentrations of targets were used for potentiometric detection of enzymatic generated intermediates or product ions. Twenty microliters of the Tris- $\mathrm{HCl}$ buffer $(2.0 \mathrm{mM}, \mathrm{pH}$ $8.0)$ solution containing $50 \mathrm{mM} p$-NPP was added and reacted for $8 \mathrm{~min}$. Chronopotentiometric measurements were carried out in $0.5 \mathrm{~mL}$ of Tris- $\mathrm{HCl}$ buffer solution containing $2.0 \times 10^{-4}$ $\mathrm{M}$ TMB and $0.02 \mathrm{M} \mathrm{H}_{2} \mathrm{O}_{2}$. In this work, the ISE potential was first recorded in Tris- $\mathrm{HCl}$ buffer $(2.0 \mathrm{mM}, \mathrm{pH} 8.0)$ containing MBs in the absence of target DNA to obtain a baseline. The potential difference between the baseline and the potential response in the presence of target DNA at various concentrations was used for quantification of the bacterial concentration. All of the experiments were carried out at room temperature $\left(25 \pm 2{ }^{\circ} \mathrm{C}\right)$. 


\section{RESULTS AND DISCUSSION}

Sensing Principle. Magnetic beads (MBs) with attractive features such as ease of synthesis, versatile surface modification strategies, and unique magnetic properties make them an ideal platform for biosensing, bioseparation, and biocatalysis. ${ }^{40}$ Scheme 1 illustrates the principle of the magnetic beads-

Scheme 1. (A) Representation of the Potentiometric Assay for Simultaneous Detection of Two Molecules; (B) Schematic Illustration of the Extraction of Anions ( $a, A^{-}$) and Cations $\left(\mathrm{b}, \mathrm{B}^{+}\right)$into the Polymeric Membrane under Current-Controlled Conditions; and (C) Pulsed Galvanostatic Control of Enzymatic-Generated Indicator Ions for Potentiometric Sensing ${ }^{a}$

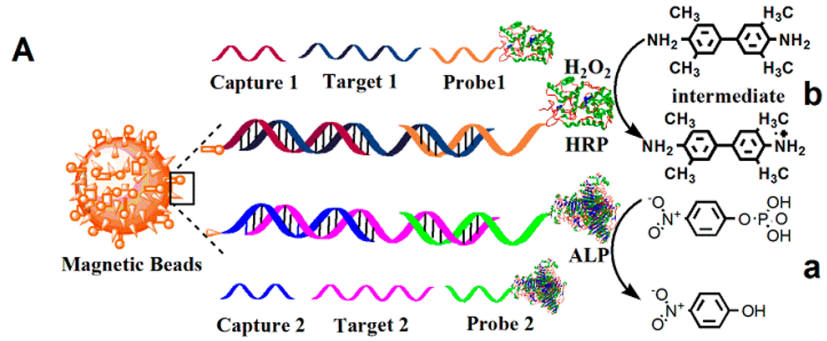

B
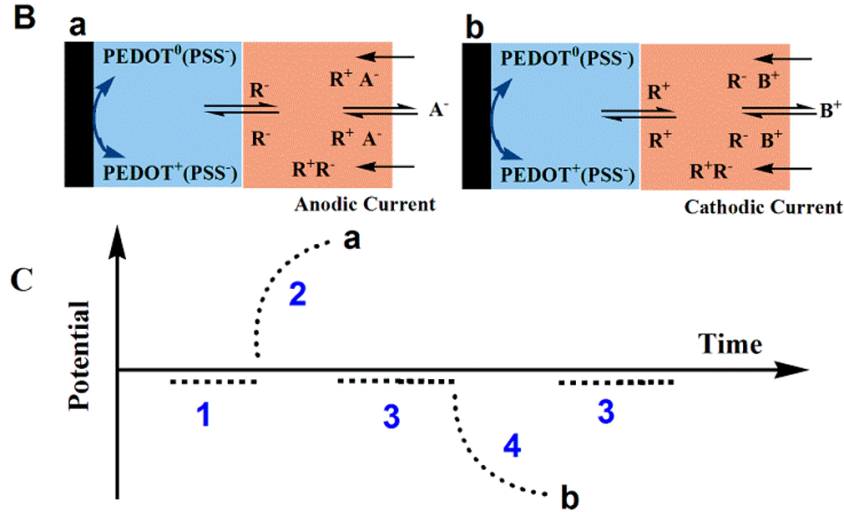

${ }^{a}$ The measured potential is (1) open-circuit potential, chronopotential for anions, (3) baseline potential, and chronopotential for cations.

enzyme sandwich assay for simultaneous detection of dual targets. Two target DNAs, associated with Escherichia coli O157:H7 and Staphylococcus aureus, were used to validate the sensing principle. The sandwich-type detection strategy involves four main steps: (i) immobilization of the capture probes on MBs via biotin-avidin interactions, (ii) capture of the target DNAs by the probe-modified MBs, (iii) link to an enzyme-conjugated signal probe, and (iv) chronopotentiometric detection of the enzymatic generated intermediates or product ions. The introduction of magnetic separation facilitates the manipulation of the detection process and eliminates the interferences for potentiometric measurements.

Recently, our group found that ion exchanger-based polymeric membrane electrode can be used as a transducer for biosensing based on HRP or peroxidase mimetics $-\mathrm{H}_{2} \mathrm{O}_{2}$ oxidation reaction. ${ }^{41,42}$ Because the accumulation of enzymatic generated ionic species in the interfacial layer of the membrane leads to an irreversible potentiometric response, the electrode is either single use or needs tedious regeneration process. In addition, all of these electrodes are conventional electrodes with inner solution arrangement, which may impede their miniaturization and practical applications.

In this work, a solid-contact ion-sensitive electrode using poly(3,4-ethylenedioxythiophene) doped with the bulky polyanionpoly(sodium 4-styrenesulfonalte) PEDOT(PSS) as ion-to-electron transducer was designed. PEDOT(PSS) was used with a high-conductivity grade, which contains both PEDOT $^{+}$and PEDOT $^{0.43}$ The electron transfer occurs reversibly at the electrode and solid-contact interface between the redox couple $\mathrm{PEDOT}^{+} / \mathrm{PEDOT}^{0}$. Because of its large redox capacitance and small diffusion resistance, PEDOT(PSS) is a promising conducting polymer for ion-to-electron transduction. ${ }^{44}$ Furthermore, reversible oxidation of the polymer bulk is connected with the ion transport originating from the separation and migration of the ion-exchanger of ETH 500 in the ion-selective membrane under galvanostatic polarization. The electrode membrane with a lipophilic salt ETH 500 $\left(\mathrm{R}^{+} \mathrm{R}^{-}\right)$possesses no ion exchanger properties under zerocurrent conditions. Under periodic galvanostatic polarization, the lipophilic cations $\left(\mathrm{R}^{+}\right)$and anions $\left(\mathrm{R}^{-}\right)$will separate and migrate in opposite directions (Scheme 1B). Meanwhile, the transfer of target ions from the sample solution into the membrane phase will produce a reproducible chronopotentiometric response. Because of the large molecular weight of the PSS, $\mathrm{R}^{-}$ions reversibly participate in the ion exchange at the electrode and solid-contact interface. ${ }^{45}$

Potentiometric measurement protocols based on current polarization are shown in Scheme 1C. The macro-commandcontrolled procedures for measuring zero-current and currentdependent potentials were designed. ${ }^{46}$ In the HRP-based signal amplification method, the open-circuit potential is first recorded. Next, a cathodic current is applied on the electrode, which results in a cation flux from the sample to the membrane. During the chronopotentiometric measurement, the abrupt potential decrease is attributed to the IR voltage change. ${ }^{47}$ The potential is then increasing linearly with time, which is due to the extraction of cations in the sample solution. Following the cathodic current pulse, the membrane is restored by using a controlled voltage at the open-circuit potential that enables the recovery of the membrane for multiple consecutive measurements. In the ALP-based signal amplification method, however, an anodic current is used for the anion extraction. It should be noted that the controlled protocols based on reverse current polarization can also be adopted for membrane recovery and consecutive measurements. ${ }^{48}$ In the pulsed potentiometric methods, ions with different charges can be extracted into the sensing membrane via an external current control to produce a reproducible chronopotentiometic response. In addition, multiple consecutive measurement/restoration cycles can be done. Indeed, current pulses produce highly reversible, repeatable, and rapid response (Figure 1).

In previous research, Bobacka's group observed and investigated the presence of hysteresis for the conducting polymer layers in solid-contact ISEs. ${ }^{49}$ Moreover, the PEDOT layer tends to change resistance when potentials or currents are applied repeatedly. In this study, the electrochemical impedance spectroscopy was used to evaluate the resistance change of the electrode. As shown in Figure S1, the highfrequency semicircle, which is related to the bulk membrane resistance coupled to the contact resistance at the interface between GC or solid contact and the ion-selective PVC membrane, ${ }^{50}$ is unchanged after 12 consecutive measurements. The equivalent circuit, which was used to fit the impedance 


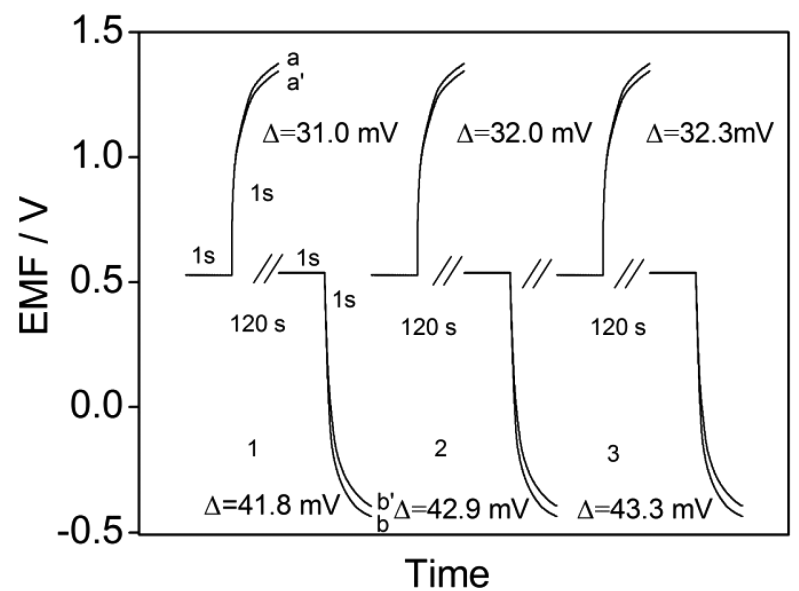

Figure 1. Potentiometric responses of the pulsed galvanostaticcontrolled ion-selective electrode without $(\mathrm{a}, \mathrm{b})$ and with $0.4 \mu \mathrm{g} \mathrm{mL}^{-1}$ AP-conjugated avidin $\left(\mathrm{a}^{\prime}\right)$ and $0.2 \mu \mathrm{g} \mathrm{mL} \mathrm{m}^{-1}$ HRP-conjugated streptavidin $\left(\mathrm{b}^{\prime}\right)$ in $0.5 \mathrm{~mL}$ of Tris buffer contained $2.0 \times 10^{-4} \mathrm{M}$ TMB and $0.02 \mathrm{M} \mathrm{H}_{2} \mathrm{O}_{2}$. The AP-conjugated avidin and HRPconjugated streptavidin were incubated in $20 \mu \mathrm{L}$ of hybridization buffer containing $50 \mathrm{mM} p$-NPP at room temperature for $8 \mathrm{~min}$. Three (1-3) consecutive measurements were carried out.

spectra, is shown in Figure S1B. The $R_{c t}$ which represents charge-transfer resistance, was 19090, 19160 , and $20050 \Omega$ after 0,12 , and 24 consecutive measurements. The IR voltage change was calculated to be $4.8 \mathrm{mV}$, indicating that the membrane resistance remains stable during each pulse, with no apparent drift. The potential deviation can be further reduced by using applied current with smaller amplitude. ${ }^{45}$

Optimization of Detection Conditions. According to our previous research, TMB and $p$-NPP were selected as enzyme substrates for HRP-based and ALP-based sandwich assays, respectively. ${ }^{38,41}$ Because enzyme stability and activity depend on $\mathrm{pH}$ value and buffer solution, these parameters were optimized. To gain the optimal catalytic activity of both ALP and HRP, $\mathrm{pH} 8.0$ was selected for potentiometric measurement. Under the $\mathrm{pH}$ value, $\mathrm{TMB}\left(\mathrm{p} K_{\mathrm{a}}=4.0\right)$ itself is mainly nonionic. However, the oxidation intermediates of TMB such as the free radical, diimine, and charge transfer complex of the diamine product $\left(\mathrm{p} K_{\mathrm{a}}>9.0\right)$ are positively charged, ${ }^{42}$ which enables the current-controlled extraction of these intermediates into the polymeric membrane to produce potentiometric responses. For the ALP-based sandwich assay, the product ions ( $p$-nitrophenol, $\left.\mathrm{p} K_{\mathrm{a}}=7.14\right)$ with a high lipophilicity are anions at $\mathrm{pH}$ 8.0, which favors the potentiometric detection of it by pulsed galvanostatic control of the polymeric membrane ion-selective electrode.

Because the extraction process is controlled by current pulse in two opposite directions, both cations and anions in the buffer solution may interfere with the potentiometric measurement. Thus, the lipophilicity of the interfering ions and the ionic strength of the buffer solution should be taken into consideration. In this work, $\mathrm{pH}$ 8.0 PBS and Tris buffer solutions were investigated. When $\mathrm{pH}$ 8.0 PBS was used for potentiometric measurement, a large potential change can only be observed for the ALP-based sandwich assay for Staphylococcus aureus (Figure 2A). This phenomenon may result from the inactivation of the HRP by phosphate itself in the buffer, which has been observed before. ${ }^{51}$ Moreover, the potential change becomes smaller in the presence of a larger amount of interference ions such as chloride ions in Tris buffer
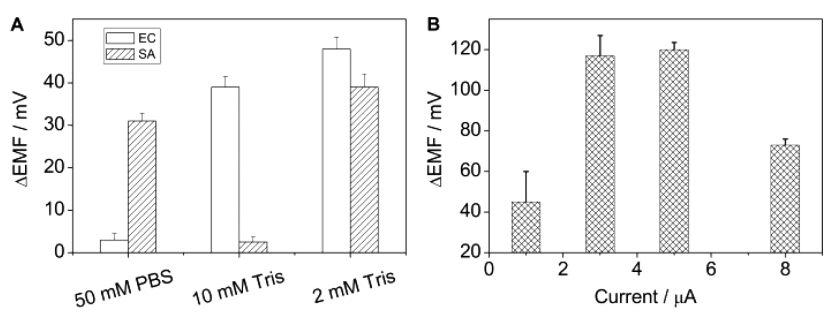

Figure 2. (A) Potentiometric responses of the ISE to $10^{-10} \mathrm{M}$ target nucleic acid sequence of Escherichia coli O157:H7 (EC) and Staphylococcus aureus (SA) in the $50 \mathrm{mM}, \mathrm{pH} 8.0 \mathrm{PBS}$, the $10 \mathrm{mM}$, $\mathrm{pH} 8.0$ Tris- $\mathrm{HCl}$, and the $2.0 \mathrm{mM}$, pH 8.0 Tris- $\mathrm{HCl}$ buffer solutions. (B) Potential responses of the ISE to $10^{-10} \mathrm{M}$ target nucleic acid sequence of Escherichia coli O157:H7 with different magnitude of current. $10 \mu \mathrm{L}$ of $0.02 \mathrm{mg} \mathrm{mL}^{-1} \mathrm{HRP}$ enzyme were added into $0.5 \mathrm{~mL}$ Tris- $\mathrm{HCl}$ buffer solution containing $2.0 \times 10^{-4} \mathrm{M} \mathrm{TMB}$ and $0.02 \mathrm{M}$ $\mathrm{H}_{2} \mathrm{O}_{2}$. Each error bar represents one standard deviation for three measurements.

solution (the selectivity coefficient of $p$-nitrophenol over chloride ion is $-2.80 \pm 0.14){ }^{46}$ Thus, $2.0 \mathrm{mM} \mathrm{pH} 8.0$ Tris buffer with lower ionic strength was selected in the subsequent study.

Because the extraction process is controlled instrumentally, the ion-extraction process can be regulated by magnitude and duration of the current pulse. As shown in Figure 2B, the potential change is increased with the amplitude of applied current in the current region from 1 to $5 \mu \mathrm{A}$. At currents larger than $5 \mu \mathrm{A}$, the potential change becomes smaller, which may due to the extraction of interfering ions into the membrane. ${ }^{27}$ The phenomenon on potential change can be observed for both HRP-based and ALP-based sandwich assays. Experiments also revealed that the potential change remains almost constant after the current pulse duration of $1 \mathrm{~s}$. Moreover, the short current pulse allows electrode recovery and multiple measurements to be done in a relatively short period. Therefore, a current pulse of $1 \mathrm{~s}$ duration was used in subsequent experiments. It should be noted that the applied current could lead to a localized depletion at a transition time, which has also been adopted as the analytical signal (Figure S2). ${ }^{16}$

Detection of Single-Component DNA Sequence. The $\mathrm{H}_{2} \mathrm{O}_{2}$-mediated oxidation of TMB catalyzed by peroxidase can generate cationic intermediates that irreversibly can be extracted into a cation-changer doped polymeric liquid membrane electrode to induce potentiometric responses. Thus, the conventional ion-exchanger-based electrode shows poor reversibility. However, cationic intermediates can be either extracted into or stripped out of the membrane via current/ voltage control by using the chronopotentiometric method. Therefore, this MBs-enzyme sandwich is applicable for rapid and reversible DNA sequence detection.

As shown in Figure 3A, the oxidation intermediates of TMB can be extracted into the membrane to produce a chronopotentiometric response. Because of the difficulty in obtaining a pure and stable intermediate, it is difficult to obtain the lower detection limit of the electrode responsive to the TMB oxidation intermediates. However, our previous report has shown that the detection limit of the electrode toward TMB oxidation intermediates and $p$-nitrophenol should be lower than $10^{-6} \mathrm{M}^{42,46}$ Under the optimum conditions, the chronopotential increases with increasing Escherichia coli O157:H7 DNA concentration, and the potential change was proportional to DNA concentration in the range from $0.1 \mathrm{pM}$ 

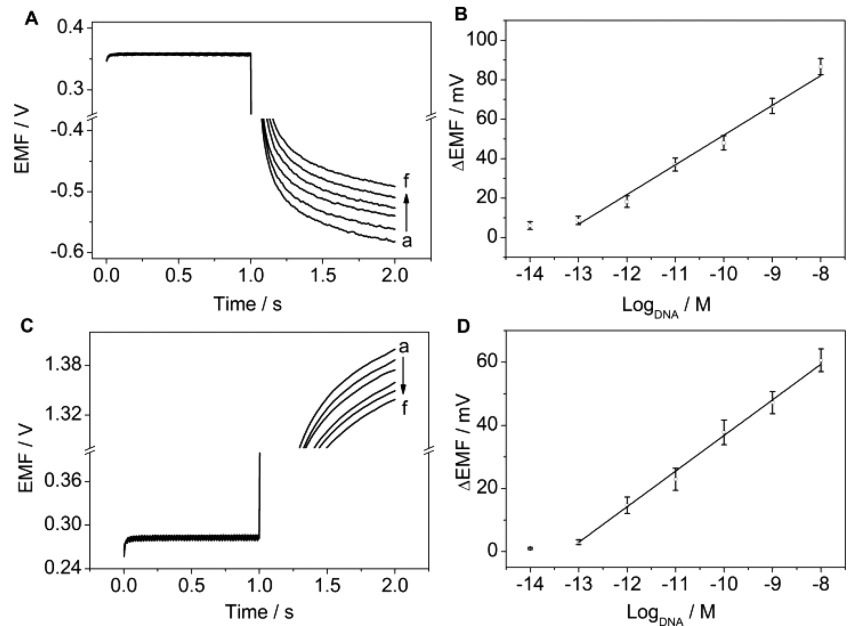

Figure 3. (A) Potentiometric responses of the electrode in $0.5 \mathrm{~mL}$ of pH 8.0, $2.0 \mathrm{mM}$ Tris-HCl with (a) 0 , (b) $10^{-12}$, (c) $10^{-11}$, (d) $10^{-10}$, (e) $10^{-9}$, and (f) $10^{-8} \mathrm{M}$ different concentrations of Escherichia coli O157:H7 target sequence (HRP-labeled assay). (B) Calibration curve for the Escherichia coli O157:H7 nucleic acid sequence detection. (C) Potentiometric responses of the electrode in $0.5 \mathrm{~mL}$ of $\mathrm{pH} 8.0,2.0$ $\mathrm{mM}$ Tris-HCl with (a) 0 , (b) $10^{-12}$, (c) $10^{-11}$, (d) $10^{-10}$, (e) $10^{-9}$, and (f) $10^{-8} \mathrm{M}$ different concentrations of Staphylococcus aureus target sequence (ALP-labeled assay). (D) Calibration curve for Staphylococcus aureus nucleic acid sequence detection. Each error bar represents one standard deviation for three measurements.

to $10 \mathrm{nM}$ (Figure 3B). A detection limit was calculated as 70 $\mathrm{fM}(3 \sigma)$. This value compares favorably with those reported for other electrochemical DNA hybridization assays using similar enzyme labels. ${ }^{52,53}$ On the other hand, by applying an anodic current, anions can be extracted into the same polymeric membrane to produce the chronopotentiometric signal (Figure $3 \mathrm{C})$. By using the proposed membrane electrode, potentiometric detection based on the ALP-labeled sandwich assay was developed. Indeed, a current-dependent potential difference was observed for Staphylococcus aureus DNA with concentrations greater than $0.1 \mathrm{pM}$. As shown in the figure in $3 \mathrm{D}$, the potential change exhibits a linear range at the concentration from $0.1 \mathrm{pM}$ to $10 \mathrm{nM}$. The detection limit for Staphylococcus aureus DNA was $40 \mathrm{fM}(3 \sigma)$. Additional experiments revealed that the cross-reactivity between Escherichia coli O157:H7 DNA and Staphylococcus aureus DNA was negligible.

Simultaneous Detection of DNA Targets. MBs-enzyme sandwich assay for simultaneous detection of two DNA targets was carried out according to Scheme 1. The capture probe DNA and signal DNA were complementary to the corresponding targets and formed a sandwich structure. It was found that the enzymatic generated ions with different charges could be extracted into the sensing membrane to produce currentdependent potential responses (Figure 4). Ion discrimination was achieved as a consequence of the direction of applied current. Under optimal conditions, two bacteria nucleic acid sequences were detected simultaneously. The detection limits of Escherichia coli O157:H7 DNA and Staphylococcus aureus DNA were 120 and $54 \mathrm{fM}(3 \sigma)$. Accordingly, the solid-contact ISEs can be used to simultaneously detect two molecules. Previous research has shown that an amplification factor of $10^{4}$ can be obtained for the measurements involving a HRP label. ${ }^{54}$ The sensitivity could be improved further on the basis of signal amplification using multiple enzyme tags in a single binding event. $^{55}$
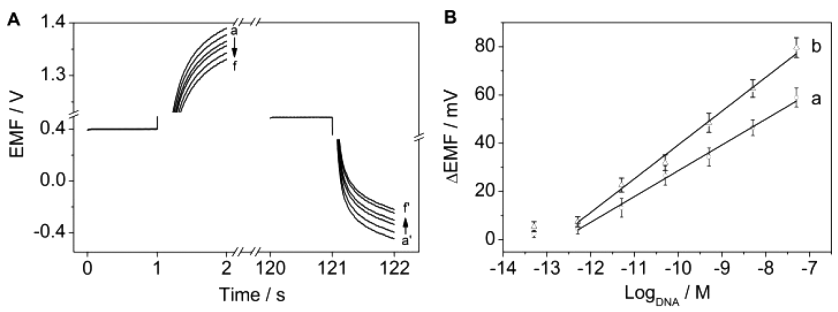

Figure 4. (A) Potentiometric responses of the ion-selective electrode in $0.5 \mathrm{~mL}$ of $\mathrm{pH} 8.0,2.0 \mathrm{mM}$ Tris- $\mathrm{HCl}$ upon addition of increasing concentration of target sequence: with (a) 0 , (b) $5 \times 10^{-12}$, (c) $5 \times$ $10^{-11}$, (d) $5 \times 10^{-10}$, (e) $5 \times 10^{-9}$, and (f) $5 \times 10^{-8} \mathrm{M}$ different concentrations of $(a-f)$ Staphylococcus and $\left(a^{\prime}-f^{\prime}\right)$ Escherichia coli O157:H7. (B) Calibration curve for (a) Staphylococcus and (b) Escherichia coli O157:H7 nucleic acid sequence detection. Each error bar represents one standard deviation for three measurements.

Evaluation of Specificity. To demonstrate the specificity, the proposed assay was challenged with nontarget DNA sequences for Salmonella and Listeria monocytogenes. As shown in Figure 5, the responses to other DNA sequences are rather
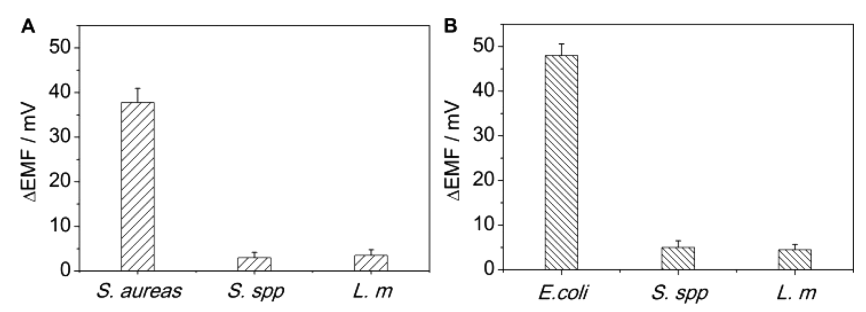

Figure 5. Potential responses of the ISE to (A) the target sequence of Staphylococcus, Salmonella, and Listeria monocytogenes using Staphylococcus capture probe and (B) the target sequence of Escherichia coli, Salmonella, Listeria monocytogenes using Escherichia coli capture probe. The concentrations of bacteria nucleic target sequence were $10^{-10} \mathrm{M}$.

negligible as compared to that to the specific target DNA sequence, thus demonstrating a high degree of specificity of the bioassay.

\section{CONCLUSION}

In summary, a potentiometric sensing strategy with ISEs that can detect two analytes in a single measurement was proposed. The pulsed galvanostatic technique offers an effective way to regulate the extraction of different charged indicator ions. As an example, a potentiometric bioassay based on different enzyme labels coupled with magnetic nanoparticles was successfully developed for simultaneous, rapid, and specific quantitation of two specific DNA targets. The introduction of magnetic separation facilitates the manipulation of the detection process and eliminates the interference for potentiometric measurements. The proposed simultaneous detection provides promising potential to detect a variety of targets by using new bioreceptors such as antibodies and aptamers.

\section{ASSOCIATED CONTENT}

\section{Supporting Information}

The Supporting Information is available free of charge on the ACS Publications website at DOI: 10.1021/acs.analchem.7b03522.

Sequences of synthetic oligonucleotides and targets as noted in text, and Figures S1 and S2 (PDF) 


\section{AUTHOR INFORMATION}

\section{Corresponding Author}

*Tel.: +86 535 2109153. Fax: +86535 2109000. E-mail: jwding@yic.ac.cn.

\section{ORCID $\odot$}

Jiawang Ding: 0000-0002-8361-9102

Wei Qin: 0000-0002-9606-7730

\section{Author Contributions}

${ }^{\S}$ J.D. and N.Y. contributed equally to this work.

\section{Notes}

The authors declare no competing financial interest.

\section{ACKNOWLEDGMENTS}

This work was financially supported by the National Natural Science Foundation of China $(21575158,21677172)$, the Instrument Developing Project of the Chinese Academy of Sciences (Y728021021), the National Key Research and Development Program of China (2016YFC1400700), and the Taishan Scholar Program of Shandong Province (TS20081159).

\section{REFERENCES}

(1) Bakker, E.; Pretsch, E. Angew. Chem., Int. Ed. 2007, 46, 56605668

(2) Bobacka, J.; Ivaska, A.; Lewenstam, A. Chem. Rev. 2008, 108, 329-351.

(3) Lindner, E.; Gyurcsanyi, R. E. J. Solid State Electrochem. 2009, 13, $51-68$.

(4) Hu, J.; Stein, A.; Bühlmann, P. TrAC, Trends Anal. Chem. 2016, $76,102-114$

(5) Bakker, E.; Bühlmann, P.; Pretsch, E. Chem. Rev. 1997, 97, 30833132

(6) Bakker, E. TrAC, Trends Anal. Chem. 2014, 53, 98-105.

(7) Bakker, E. Anal. Chem. 2016, 88, 395-413.

(8) Shvarev, A.; Bakker, E. J. Am. Chem. Soc. 2003, 125, 1119211193.

(9) Ding, J. W.; Qin, W. J. Am. Chem. Soc. 2009, 131, 14640-14641.

(10) Cuartero, M.; Crespo, G. A.; Afsharand, M. G.; Bakker, E. Anal. Chem. 2014, 86, 11387-11395.

(11) Crespo, G. A.; Cuartero, M.; Bakker, E. Anal. Chem. 2015, 87, $7729-7737$.

(12) Grygolowicz-Pawlak, E.; Bakker, E. Anal. Chem. 2010, 82, 4537-4542.

(13) Afshar, M. G.; Crespo, G. A.; Xie, X. J.; Bakker, E. Anal. Chem. 2014, 86, 6461-6470.

(14) Hupa, E.; Vanamo, U.; Bobacka, J. Electroanalysis 2015, 27, 591-594.

(15) Crespo, G. A.; Afshar, M. G.; Bakker, E. Angew. Chem., Int. Ed. 2012, 51, 12575-12578.

(16) Vanamo, U.; Hupa, E.; Yrjana, V.; Bobacka, J. Anal. Chem. 2016, $88,4369-4374$

(17) Kim, Y.; Amemiya, S. Anal. Chem. 2008, 80, 6056-6065.

(18) Si, P. C.; Bakker, E. Chem. Commun. 2009, 35, 5260-5262.

(19) Cuartero, M.; Crespo, G. A.; Bakker, E. Anal. Chem. 2016, 88, $1654-1660$.

(20) Greenawalt, P. J.; Amemiya, S. Anal. Chem. 2016, 88, 58275834.

(21) Yuan, D. J.; Cuartero, M.; Crespo, G. A.; Bakker, E. Anal. Chem. 2017, 89, 586-594.

(22) Yuan, D. J.; Cuartero, M.; Crespo, G. A.; Bakker, E. Anal. Chem. 2017, 89, 595-602.

(23) Makarychev-Mikhailov, S.; Shvarev, A.; Bakker, E. J. Am. Chem. Soc. 2004, 126, 10548-10549.

(24) Peshkova, M. A.; Koltashova, E. S.; Khripoun, G. A.; Mikhelson, K. N. Electrochim. Acta 2015, 167, 187-193.
(25) Makarychev-Mikhailov, S.; Shvarev, A.; Bakker, E. Anal. Chem. 2006, 78, 2744-2751.

(26) Gemene, K. L.; Meyerhoff, M. E. Anal. Chem. 2010, 82, 16121615.

(27) Shvarev, A.; Bakker, E. Anal. Chem. 2003, 75, 4541-4550.

(28) Wang, X. W.; Balijepalli, A. S.; Meyerhoff, M. E. Electroanalysis 2015, 27, 1823-1828.

(29) Chumbimuni-Torres, K. Y.; Dai, Z.; Rubinova, N.; Xiang, Y.; Pretsch, E.; Wang, J.; Bakker, E. J. Am. Chem. Soc. 2006, 128, 367613677.

(30) Szúcs, J.; Pretsch, E.; Gyurcsányi, R. E. Analyst 2009, 134, 1601-607.

(31) Ozdemir, M. S.; Marczak, M.; Bohets, H.; Bonroy, K.; Roymans, D.; Stuyver, L.; Vanhoutte, K.; Pawlak, M.; Bakker, E. Anal. Chem. 2013, 85, 4770-4776.

(32) Ding, J. W.; Chen, Y.; Wang, X. W.; Qin, W. Anal. Chem. 2012, 84, 2055-2061.

(33) Ding, J. W.; Li, B. W.; Chen, L. X.; Qin, W. Angew. Chem., Int. Ed. 2016, 55, 13033-13037.

(34) Numnuam, A.; Chumbimuni-Torres, K. Y.; Xiang, Y.; Bash, R.; Thavarungkul, P.; Kanatharana, P.; Pretsch, E.; Wang, J.; Bakker, E. Anal. Chem. 2008, 80, 707-712.

(35) Gonzalez-Bellavista, A.; Atrian, S.; Munoz, M.; Capdevila, M.; Fabregas, E. Talanta 2009, 77, 1528-1533.

(36) Ding, J. W.; Lei, J. H.; Ma, X.; Gong, J.; Qin, W. Anal. Chem. 2014, 86, 9412-9416.

(37) Ding, J. W.; Gu, Y.; Li, F.; Zhang, H. X.; Qin, W. Anal. Chem. 2015, 87, 6465-6469.

(38) Yu, N. N.; Ding, J. W.; Wang, W. W.; Wang, X. D.; Qin, W. Sens. Actuators, B 2016, 230, 785-790.

(39) Farabullini, F.; Lucarelli, F.; Palchetti, I.; Marrazza, G.; Mascini, M. Biosens. Bioelectron. 2007, 22, 1544-1549.

(40) Harivardhan Reddy, L.; Arias, J. L.; Nicolas, J.; Couvreur, P. Chem. Rev. 2012, 112, 5818-5878.

(41) Wang, X. W.; Qin, W. Chem. Commun. 2012, 48, 4073-4075.

(42) Wang, X. W.; Yang, Y. G.; Li, L.; Sun, M. S.; Yin, H. G.; Qin, W. Anal. Chem. 2014, 86, 4416-4422.

(43) Nilsson, D.; Robinson, N.; Berggren, M.; Forchheimer, R. Adv. Mater. 2005, 17, 353-357.

(44) Bobacka, J. Anal. Chem. 1999, 71, 4932-4937.

(45) Perera, H.; Fordyce, K.; Shvarev, A. Anal. Chem. 2007, 79, 4564-4573.

(46) Ding, J. W.; Wang, X. W.; Qin, W. ACS Appl. Mater. Interfaces 2013, 5, 9488-9493.

(47) Vanamo, U.; Bobacka, J. Electrochim. Acta 2014, 122, 316-321.

(48) Zook, J. M.; Lindner, E. Anal. Chem. 2009, 81, 5146-5154.

(49) Sjöberg-Eerola, P.; Bobacka, J.; Lewenstam, A.; Ivaska, A. Sens. Actuators, B 2007, 127, 545-553.

(50) Veder, J. P.; De Marco, R.; Clarke, G.; Chester, R.; Nelson, A.; Prince, K.; Pretsch, E.; Bakker, E. Anal. Chem. 2008, 80, 6731-6740.

(51) Bovaird, J. H.; Ngo, T. T.; Lenhoff, H. M. Clin. Chem. 1982, 28, $2423-2426$.

(52) Liu, G.; Wan, Y.; Gau, V.; Zhang, J.; Wang, L. H.; Song, S. P.; Fan, C. H. J. Am. Chem. Soc. 2008, 130, 6820-6825.

(53) Weizmann, Y.; Chenoweth, D. M.; Swager, T. M. J. Am. Chem. Soc. 2011, 133, 3238-3241.

(54) Wojciechowski, M.; Sundseth, R.; Moreno, M.; Henkens, R. Clin. Chem. 1999, 45, 1690-1693.

(55) Munge, B.; Liu, G. D.; Collins, G.; Wang, J. Anal. Chem. 2005, $77,4662-4666$ 